\title{
New Development in Selective Laser Melting of Ti-6Al-4V: A Wider Processing Window for the Achievement of Fully Lamellar $\alpha+\beta$ Microstructures
}

\author{
E.W. LUI, ${ }^{1}$ W. XU, ${ }^{1,2,3}$ A. PATERAS, ${ }^{1}$ M. QIAN $10,{ }^{1,4}$ and M. BRANDT ${ }^{1}$ \\ 1.-Centre for Additive Manufacturing, School of Engineering, RMIT University, Melbourne, \\ VIC 3000, Australia. 2.-School of Engineering, Macquarie University, Sydney, NSW 2109, \\ Australia. 3.—e-mail: wei.xu@mq.edu.au.4.—e-mail: ma.qian@rmit.edu.au
}

\begin{abstract}
Recent progress has shown that $\mathrm{Ti}-6 \mathrm{Al}-4 \mathrm{~V}$ fabricated by selective laser melting (SLM) can achieve a fully lamellar $\alpha+\beta$ microstructure using $60 \mu \mathrm{m}$ layer thickness in the as-built state via in situ martensite decomposition by manipulating the processing parameters. The potential to broaden the processing window was explored in this study by increasing the layer thickness to the less commonly used $90 \mu \mathrm{m}$. Fully lamellar $\alpha+\beta$ microstructures were produced in the as-built state using inter-layer times in the range of 1-12 s. Microstructural features such as the $\alpha$-lath thickness and morphology were sensitive to both build height and inter-layer time. The $\alpha$-laths produced using the inter-layer time of $1 \mathrm{~s}$ were much coarser than those produced with the inter-layer time of $12 \mathrm{~s}$. The fine fully lamellar $\alpha+\beta$ structure resulted in tensile ductility of $11 \%$ and yield strength of $980 \mathrm{MPa}$. The tensile properties can be further improved by minimizing the presence of process-induced defects.
\end{abstract}

\section{INTRODUCTION}

Selective laser melting (SLM) is an established commercial powder-bed fusion additive manufacturing (AM) technique. ${ }^{1}$ While a wide range of metals has been processed using AM, Ti-6Al-4V has gained the most attention because of its significant industrial applications and relatively high conventional manufacturing cost. ${ }^{2}$ The mechanical performance of extra-low-interstitial (ELI) Ti-6Al$4 \mathrm{~V}(<0.13 \% \quad \mathrm{O})$ is primarily determined by microstructural features such as their constituent phases, morphology and characteristic length scales. In the SLM of $\mathrm{Ti}-6 \mathrm{Al}-4 \mathrm{~V}$, the intrinsically rapid cooling rate of the melt pool usually results in a fully acicular $\alpha^{\prime}$-martensitic structure contained within columnar prior- $\beta$ grains. ${ }^{1,3}$ The $\alpha^{\prime}$-plates contain twins and dislocations and are supersaturated with $\mathrm{V}$. Therefore, they often lead to both low tensile ductility $(<10 \%)^{4}$ and low fracture toughness. ${ }^{5}$ Thus, post-heat treatment is necessary to decompose martensite into an $\alpha+\beta$ microstructure for improved ductility ${ }^{6}$ and toughness. ${ }^{5}$
Recent developments have shown that SLM Ti$6 \mathrm{Al}-4 \mathrm{~V}$ in the as-built state can achieve a fully lamellar $\alpha+\beta$ microstructure via in situ martensite decomposition by manipulating SLM variables, including the focal off-set distance, energy density, inter-layer time and hatch spacing (the layer thickness was fixed at $60 \mu \mathrm{m}){ }^{7-10} \mathrm{In}$ addition, tunable microstructural length scales and superior mechanical properties were achieved in SLM Ti-6Al-4V in the as-built state. These developments have made SLM of Ti-6Al-4V essentially similar to selective electron beam melting (SEBM) in terms of both the as-built microstructures and tensile properties. ${ }^{8}$ This study builds on these recent findings and focuses on SLM of Ti-6Al-4V at the $90 \mu \mathrm{m}$ layer thickness, which is less commonly used in SLM but offers potential advantages, e.g., allowing a wider processing window as well as use of coarser powder for improved cost-effectiveness. ${ }^{11,12}$ For a fixed layer thickness, preliminary research has shown that the inter-layer time is most influential in determining in situ martensite decomposition during SLM of Ti$6 \mathrm{Al}-4 \mathrm{~V}{ }^{8}$ Consequently, this study focuses on 
investigating the effect of inter-layer time and build height on the microstructure and mechanical properties of SLM-fabricated Ti-6Al-4V.

\section{EXPERIMENTAL}

Spherical gas atomized ELI Ti-6Al-4V powder (25-45 $\mu \mathrm{m}, 0.1 \% \mathrm{O}, 0.009 \% \mathrm{~N}, 0.008 \% \mathrm{C}, 0.17 \% \mathrm{Fe}$, $<0.002 \% \mathrm{H}$, TLS Technik GmbH \& Co.) was used to produce samples on a SLM $250 \mathrm{HL}$ (SLM Solutions $\mathrm{GmbH}$, argon flow, oxygen level $<0.1 \%$, chamber temperature $200^{\circ} \mathrm{C}$ ). For microstructural studies, a series of cylindrical rods $(12 \mathrm{~mm}$ in diameter, $30 \mathrm{~mm}$ in height) with varying inter-layer times $\left(t_{i}: 1,8,10 \mathrm{~s}\right)$ were vertically built onto fine lattice support structures ( 0.4 contact area ratio) at the laser power of $375 \mathrm{~W}$, layer thickness of $90 \mu \mathrm{m}$, scanning velocity of $686 \mathrm{~mm} / \mathrm{s}$, focal offset of $2 \mathrm{~mm}$, hatch spacing of $0.12 \mathrm{~mm}$ and energy density of $50.62 \mathrm{~J} / \mathrm{mm}^{3}$. Additionally, cylindrical rods of Ti$6 \mathrm{Al}-4 \mathrm{~V}$ (12 $\mathrm{mm}$ in diameter, $75 \mathrm{~mm}$ in height, $t_{i}: 1$, $5,12 \mathrm{~s}$ ) were fabricated using the same parameters and machined into tensile specimens (gauge section dimensions: $\emptyset 6 \mathrm{~mm} \times 30 \mathrm{~mm}$ as per ASTM standard E8/E8 M-09). Uniaxial tensile testing was carried out with an initial strain rate of $2.5 \times 10^{-4} \mathrm{~s}^{-1}$ on three specimens per build condition using a MTS universal testing machine $(100 \mathrm{kN})$ attached with a laser extensometer. Characterization of microstructure and fracture surfaces was performed using an ultra-high-resolution scanning electron microscopy (SEM, FEI Verios 460L). Samples for SEM analysis (backscatter) were prepared by conventional grinding and polishing (without chemical etching). For the 30 -mm-tall cylinders, specimens for microstructural analysis were obtained from the height of $15 \mathrm{~mm}$, while, for the 75-mm-tall cylinders, they were extracted from two heights, $15 \mathrm{~mm}$ and $60 \mathrm{~mm}$.

\section{RESULTS AND DISCUSSION}

Representative as-built microstructures of the 30mm-tall sample are shown in Fig. 1. All samples achieved a fully $\alpha+\beta$ lamellar microstructure because of in situ martensite decomposition. The width of the $\alpha$-laths depends strongly on the interlayer time $t_{i}$, where increasing $t_{i}$ often results in the formation of finer $\alpha$-laths. For the $30-\mathrm{mm}$-tall samples, the use of $t_{i}=1 \mathrm{~s}$ (the shortest) led to the formation of coarser $\alpha$-laths with an average thickness of $0.79 \pm 0.26 \mu \mathrm{m}$ (Fig. 2a). Increasing $t_{i}$ from $1 \mathrm{~s}$ to $8 \mathrm{~s}$ resulted in finer $\alpha$-laths of $0.52 \pm 0.17 \mu \mathrm{m}$, while further prolonging $t_{i}$ to $10 \mathrm{~s}$ led to a slight microstructural change with an average $\alpha$-lath thickness of $0.54 \pm 0.18 \mu \mathrm{m}$. This indicates that the variation in microstructure is minimal for $t_{i}$ longer than $8 \mathrm{~s}$ in the $30-\mathrm{mm}$-tall sample made using a layer thickness of $90 \mu \mathrm{m}$.

The $\alpha$-lath thickness at the build height of $15 \mathrm{~mm}$ in the 75-mm-tall samples followed a similar trend with increasing $t_{i}$ (Fig. 2a). However, using $t_{i}=1 \mathrm{~s}$
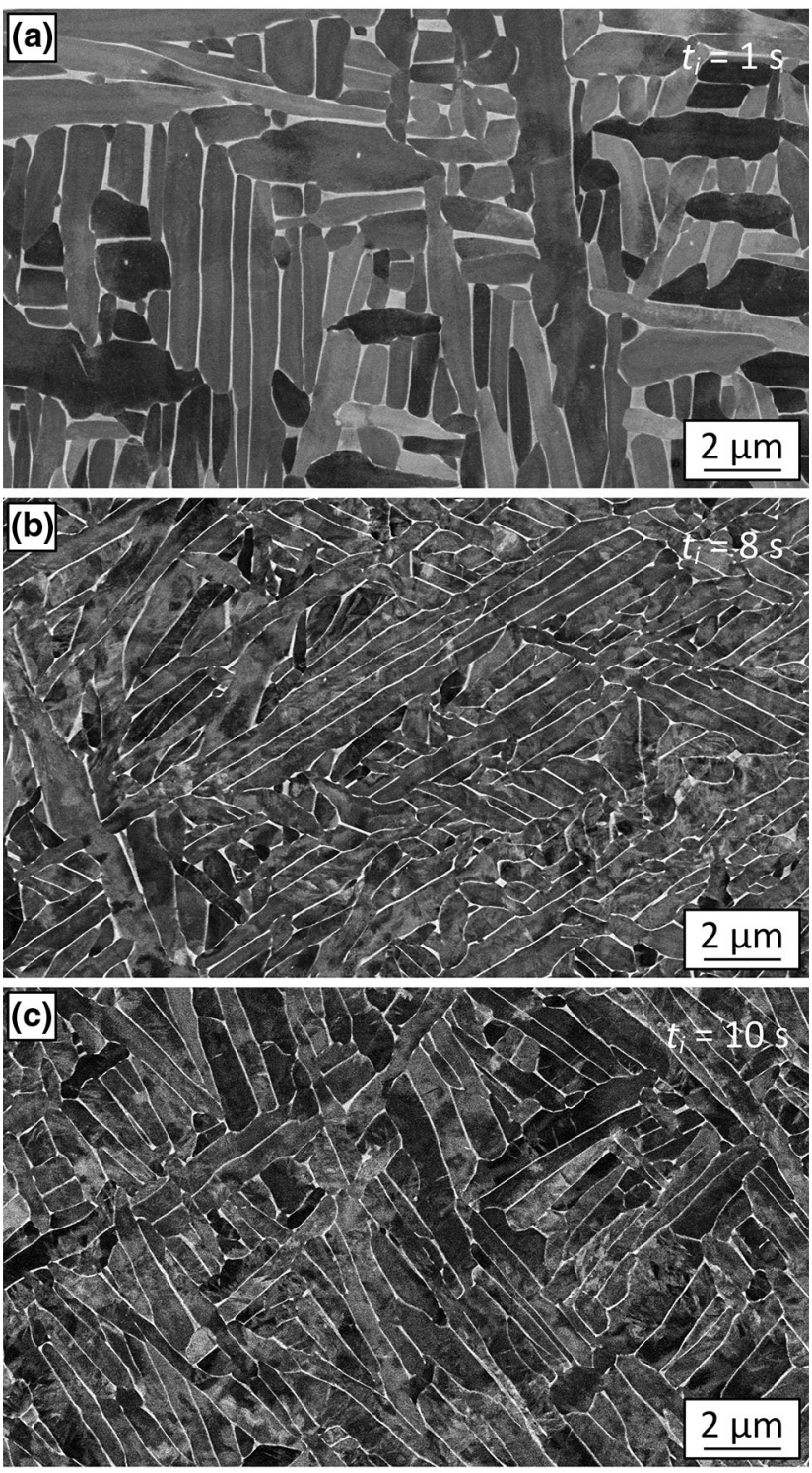

Fig. 1. Microstructures at the height of $15 \mathrm{~mm}$ in the SLM-fabricated 30-mm-tall samples with inter-layer times of (a) $1 \mathrm{~s}$, (b) $8 \mathrm{~s}$ and (c) $10 \mathrm{~s}$. The $\beta$ phase has a bright contrast, and the $\alpha$ phase has a gray contrast.

resulted in much coarser $\alpha$-laths $(2.94 \pm 0.97 \mu \mathrm{m}$, Figs. 2a and 3a) than those achieved at the height of $15 \mathrm{~mm}$ in the 30 -mm-tall samples $(0.79 \pm 0.26 \mu \mathrm{m}$, Figs. $1 \mathrm{a}$ and $2 \mathrm{a}$ ). The decrease in $\alpha$-lath thickness with increasing $t_{i}$ was also found to be more pronounced, being reduced by $71 \%$ with increasing $t_{i}$ from $1 \mathrm{~s}$ to $5 \mathrm{~s}(0.84 \pm 0.30 \mu \mathrm{m})$, followed by a further reduction of $65 \%$ from $5 \mathrm{~s}$ to $12 \mathrm{~s}$ $(0.30 \pm 0.09 \mu \mathrm{m})$. This indicates that in situ martensite decomposition during SLM of Ti-6Al$4 \mathrm{~V}$ at the layer thickness of $90 \mu \mathrm{m}$ is more sensitive to $t_{i}$ for taller samples. The $\alpha+\beta$ lamellar microstructures produced in the $75-\mathrm{mm}$-tall samples were coarser than those in the $30-\mathrm{mm}$-tall samples (Figs. 3a versus 1a). To determine the microstructure homogeneity along the build 


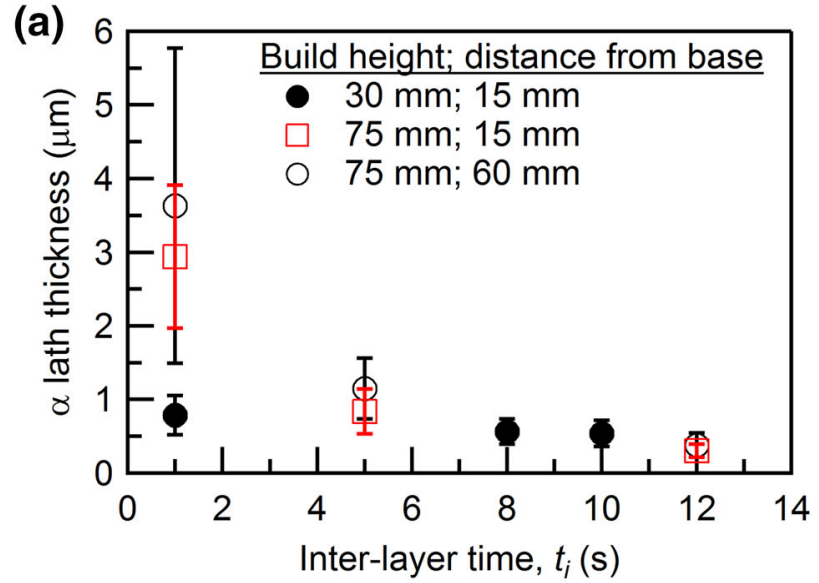

(b)

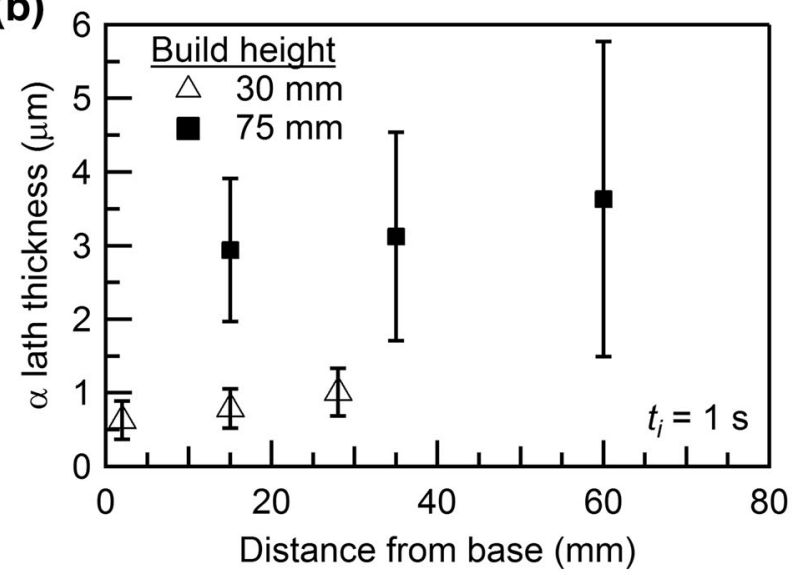

Fig. 2. Variation of the $\alpha$-lath thickness in the SLM-fabricated 30$\mathrm{mm}$ - and 75-mm-tall samples as a function of (a) inter-layer time at a specific height and (b) height along the build direction at inter-layer time of $1 \mathrm{~s}$.

direction of the 75-mm-tall sample, the microstructures at the heights of $15 \mathrm{~mm}, 35 \mathrm{~mm}$, and $60 \mathrm{~mm}$ with $t_{i}=1 \mathrm{~s}$ were examined (Fig. 3 ), and the $\alpha$-lath thickness increased marginally from $2.94 \mu \mathrm{m} \pm$ $0.97 \mu \mathrm{m}$ at $15 \mathrm{~mm}$, to $3.12 \pm 1.42 \mu \mathrm{m}$ at $35 \mathrm{~mm}$ and then to $3.63 \pm 2.14 \mu \mathrm{m}$ at $60 \mathrm{~mm}$ (Fig. $3 \mathrm{~b}$ ). The $\alpha$-laths at the bottom (Fig. 3a) were finer than those in the middle (Fig. $3 \mathrm{~b}$ ) and the upper sections (Fig. 3c). A similar trend was found in the 30-mmtall sample (Fig. $2 \mathrm{~b}, 0.63 \pm 0.26 \mu \mathrm{m}$ at $2 \mathrm{~mm}$, $0.79 \pm 0.26 \mu \mathrm{m}$ at $15 \mathrm{~mm}, \quad 1.01 \pm 0.32 \mu \mathrm{m}$ at $28 \mathrm{~mm}$ ). Figure $2 \mathrm{~b}$ indicates that the variation of microstructure along the build height is marginal in both the $30-\mathrm{mm}$ - and $75-\mathrm{mm}$-tall samples. The key innovation we have demonstrated here is that SLMfabricated $\mathrm{Ti}-6 \mathrm{Al}-4 \mathrm{~V}$ can achieve a fully lamellar $\alpha+\beta$ microstructure in the as-built state at the layer thickness of $90 \mu \mathrm{m}$ and this can enable much larger parts to be built with a wider processing window.

In Ti-6Al-4V, $\beta \rightarrow \alpha^{\prime}$ martensitic transformation occurs when the cooling rate is greater than $\sim 410 \mathrm{~K} / \mathrm{s},{ }^{13,14}$ and massive transformation takes place when reducing the cooling rate to the range of
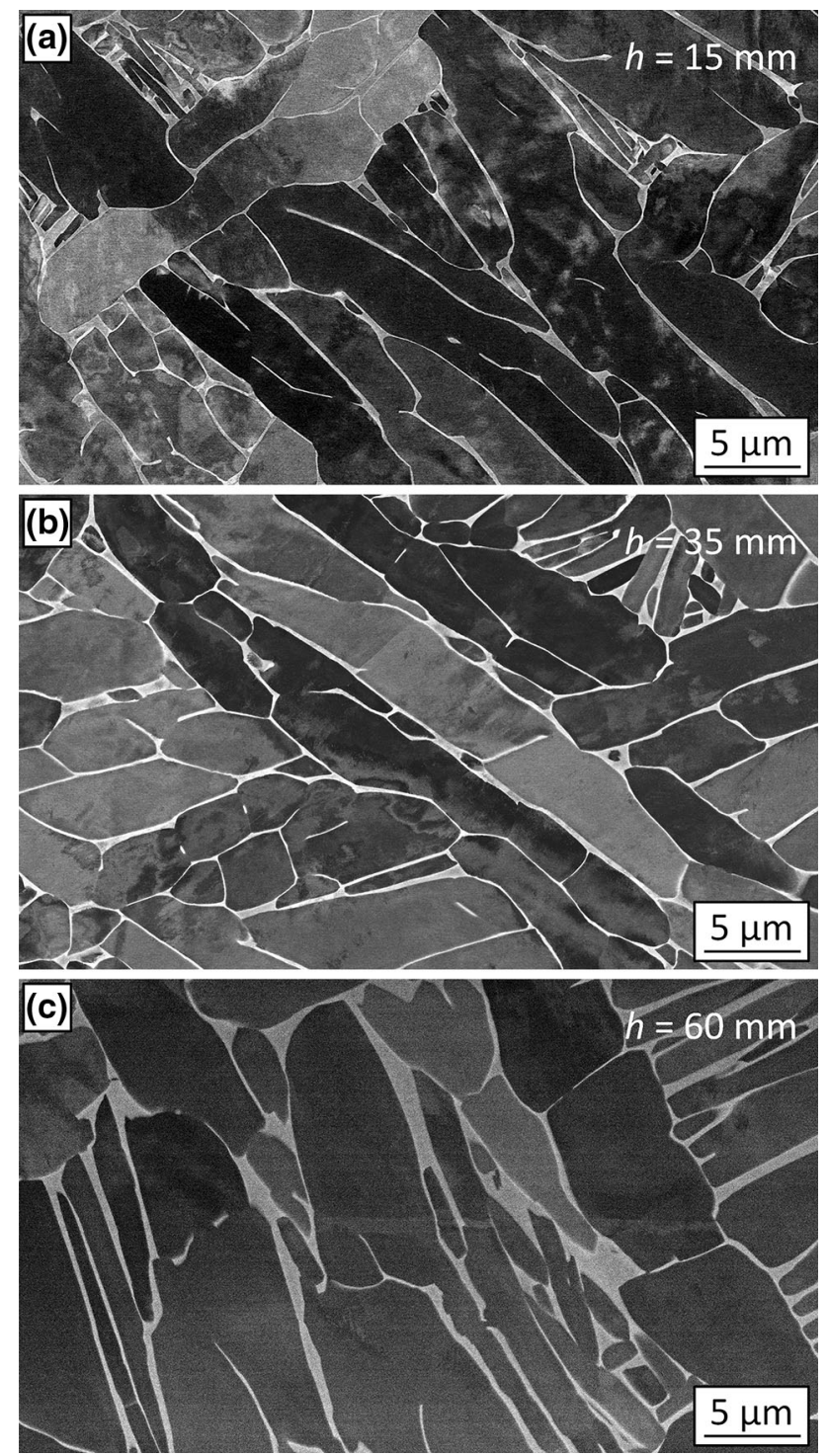

Fig. 3. Microstructure variation along the build direction in the SLMfabricated $75-\mathrm{mm}$-tall sample with an inter-layer time of $1 \mathrm{~s}$. (a) $15 \mathrm{~mm}$, (b) $35 \mathrm{~mm}$ and (c) $60 \mathrm{~mm}$. The $\beta$ phase has a bright contrast, and the $\alpha$ phase has a gray contrast.

$20-410 \mathrm{~K} / \mathrm{s}$. Further decreasing the cooling rate to below $20 \mathrm{~K} / \mathrm{s}$ leads to the formation of lamellar $\alpha$ plates in the prior $\beta$ grains. During SLM, the cooling rate of the melt pool during solidification is typically in the range of $10^{3}-10^{5} \mathrm{~K} / \mathrm{s}{ }^{2}$ The subsequent solidstate cooling process occurs at different cooling rates specific to build height for fixed SLM parameters. The presence of continuous grain boundary (GB) $\alpha$ and coarse $\alpha$-laths at the height of $60 \mathrm{~mm}$ in the 75mm-tall samples with $t_{i}=1 \mathrm{~s}$ (Fig. 4) are indicative of slow cooling rates and/or high temperature retention during a certain period of the solid-state cooling process as a result of the new processing parameters adopted in this study. As a result of a longer period of continuous subsequent heating, noticeable coarsening of the $\alpha$-laths occurred at the 


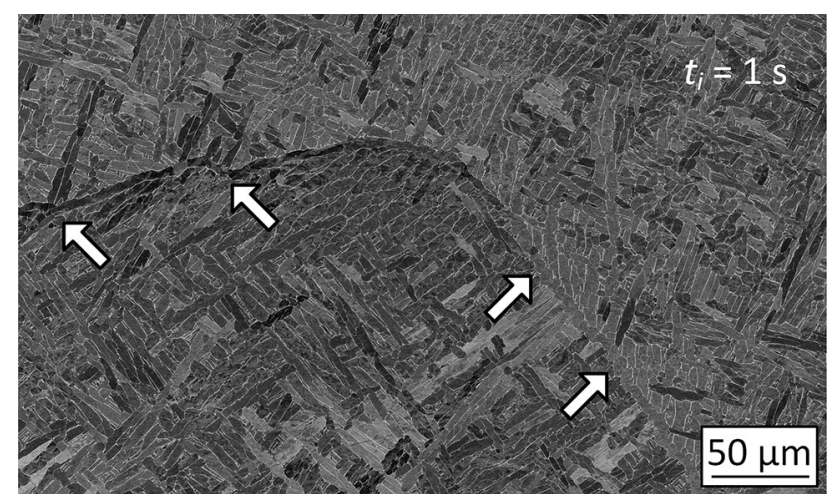

Fig. 4. Microstructure at the height of $60 \mathrm{~mm}$ in the SLM-fabricated $75-\mathrm{mm}$-tall sample with an inter-layer time of $1 \mathrm{~s}$, showing coarse $\alpha$-laths and continuous GB $\alpha$ (arrowed).

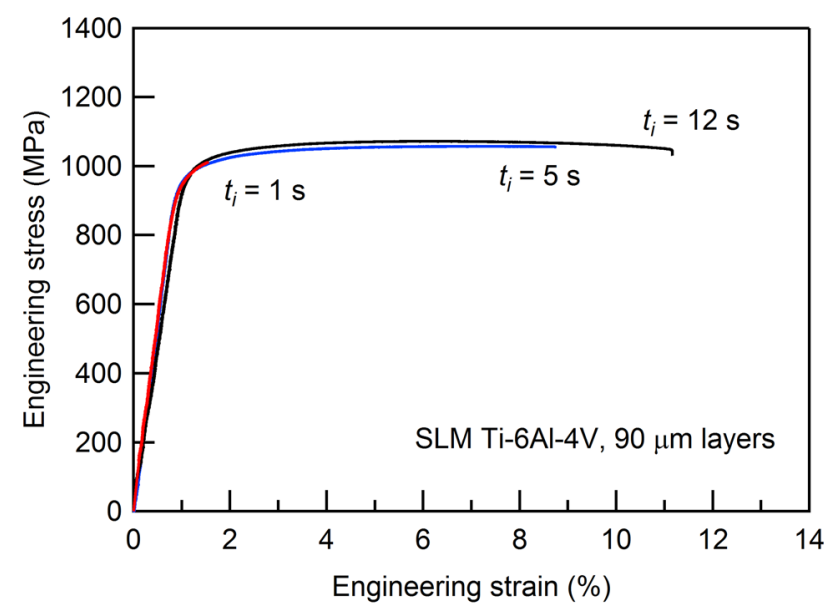

Fig. 5. Engineering tensile stress-strain curves of the SLM-fabricated Ti-6Al-4V samples produced using different inter-layer times.

same height in the 75-mm-tall samples as the 30mm-tall samples (Fig. 2b). This also led to a greater extent of $\alpha$-lath globularization.

Figure 5 shows the engineering tensile stressstrain curves for the 90- $\mu$ m-layer samples made with inter-layer times of $1 \mathrm{~s}, 5 \mathrm{~s}$, and $12 \mathrm{~s}$. All three samples have similar yield stress of $\sim 980 \mathrm{MPa}$. However, the sample built with $t_{i}=1 \mathrm{~s}$ fractured shortly upon yielding. In contrast, samples built with $t_{i}=12 \mathrm{~s}$ achieved tensile ductility of $11 \%$ in the as-built state. This distinct discrepancy, although unexpected, can be explained by the process-induced defects (porosity and lack of fusion) as shown on the fracture surface (Fig. 6). An analysis of the fracture surface revealed that the percentage of defects (area) and average defect size are respectively $16 \%$ and $59.4 \mu \mathrm{m}$ for $t_{i}=1 \mathrm{~s}, 13.4 \%$ and $56.6 \mu \mathrm{m}$ for $t_{i}=5 \mathrm{~s}$, and $13.8 \%$ and $43.3 \mu \mathrm{m}$ for $t_{i}=12 \mathrm{~s}$. The pore size for $t_{i}=1 \mathrm{~s}$ is skewed heavily to larger sizes in which $24 \%$ of the pores are $>80 \mu \mathrm{m}$ compared to $18 \%$ for $t_{i}=5 \mathrm{~s}$ and a7\% for
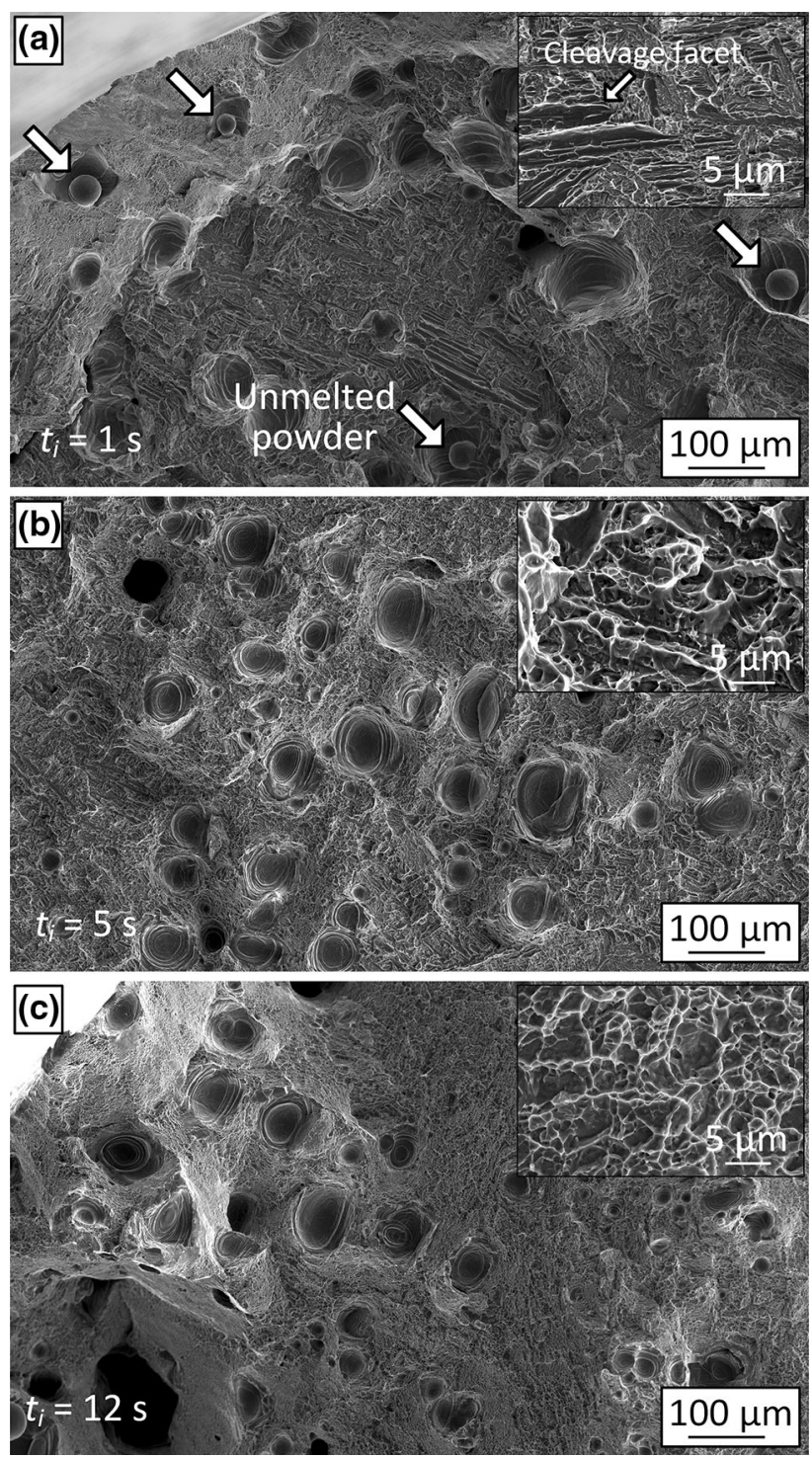

Fig. 6. Tensile fracture surfaces of SLM-fabricated Ti-6Al-4V samples with different inter-layer times of (a) $1 \mathrm{~s}$, (b) $5 \mathrm{~s}$ and (c) $12 \mathrm{~s}$. The insets are high-magnification SEM micrographs showing detailed features of the fracture surfaces.

$t_{i}=12 \mathrm{~s}$. In addition, for the sample built with $t_{i}=1 \mathrm{~s}$, a few un-melted powder particles were also observed within these pores (Fig. 6a, arrowed), while the fracture surfaces consisted of mostly quasi-cleavage facets (inset). This is possibly due to the presence of both lack of fusions and continuous GB $\alpha$. With $t_{i}=5 \mathrm{~s}$ (Fig. 6b), the fracture surface showed a mixture of quasi-cleavage facets and ductile dimples, while with $t_{i}=12 \mathrm{~s}$ (Fig. 6c), ductile dimples were dominant with a limited presence of quasi-cleavage facets. The trend of quasi-cleavage facets increasing with decreasing $t_{i}$ corresponds well with the decreasing trend in tensile ductility obtained from those samples. 
It was found that defects were consistently more prevalent in the 75-mm-tall samples than in the 30mm-tall samples. Although the exact reason is unclear, the slower cooling rate with increasing build height, as evident from the much coarser microstructure observed in the 75-mm-tall samples, may have played an influential role. It is likely that the melt pool stability has changed as a result of the changed temperature profiles. Further work is needed to clarify this in the future.

\section{SUMMARY}

- Fully lamellar $\alpha+\beta$ microstructures were produced in SLM-fabricated Ti-6Al-4V using a layer thickness of $90 \mu \mathrm{m}$. The build height and inter-layer time are both influential in determining the $\alpha$-lath thickness and morphology. The influence of build height on $\alpha$-lath thickness is more pronounced with the use of shorter interlayer times.

- Tensile fractography showed a noticeable presence of process-induced defects in the 75-mm-tall samples, which, together with the presence of continuous GB $\alpha$, resulted in low ductility for those with coarse lamellar structures $\left(t_{i}\right.$ of $\left.1 \mathrm{~s}\right)$. Fine lamellar microstructures $\left(t_{i}\right.$ of $\left.12 \mathrm{~s}\right)$ proved to be less sensitive to the presence of similar defects and achieved a good combination of tensile ductility (11\%) and yield strength $(980 \mathrm{MPa})$ in the as-built state.

- Both the microstructural and tensile property results obtained from this study are promising for broadening the processing window to achieve fully lamellar $\alpha+\beta$ microstructures for SLM of Ti-6Al-4V. Further work is needed to fine-tune the processing parameters with respect to different sample dimensions.

\section{ACKNOWLEDGEMENTS}

This project was funded by the Australian Research Council (ARC) through ARC DP150104719. WX appreciates financial support from the Macquarie University Research Development Grants (9201601532). The authors acknowledge the technical assistance of the RMIT Microscopy and Microanalysis Facility.

\section{REFERENCES}

1. L. Thijs, F. Verhaeghe, T. Craeghs, J.V. Humbeeck, and J.P. Kruth, Acta Mater. 58, 3303 (2010).

2. M. Qian, W. Xu, M. Brandt, and H.P. Tang, MRS Bull. 41, 775 (2016).

3. B. Vandenbroucke and J.P. Kruth, Rapid Prototyping J. 13, 196 (2007).

4. G. Lütjering, Mat. Sci Eng. A. 243, 32 (1998).

5. J.J. Lewandowski and M. Seifi, Ann Rev Mater Res. 46, 151 (2016).

6. T. Vilaro, C. Colin, and J.D. Bartout, Metall. Mater. Trans. A 42, 3190 (2011).

7. W. Xu, S. Sun, J. Elambasseril, Q. Liu, M. Brandt, and M. Qian, JOM 67, 668 (2015).

8. W. Xu, E.W. Lui, A. Pateras, M. Qian, and M. Brandt, Acta Mater. 125, 390 (2017).

9. P. Barriobero-Vila, J. Gussone, J. Haubrich, S. Sandlöbes, J. Da Silva, P. Cloetens, N. Schell, and G. Requena, Materials 10, 268 (2017).

10. W. Xu, M. Brandt, S. Sun, J. Elambasseril, Q. Liu, K. Latham, K. Xia, and M. Qian, Acta Mater. 85, 74 (2015).

11. M. Ma, Z. Wang, M. Gao, and X. Zeng, J. Mater. Process. Tech. 215, 142 (2015).

12. S. Bremen, W. Meiners, and A. Diatlov, Laser Tech. J. 9, 33 (2012).

13. J. Sieniawski, W. Ziaja, K. Kubiak, and M. Motyka, in Titanium Alloys-Advances in Properties Control, ed. J. Sieniawski and W. Ziaja (InTech, Rijeka, 2013), p. 69.

14. T. Ahmed and H.J. Rack, Mater. Sci. Eng. A 243, 206 (1998). 